\title{
IS UNDERGRADUATE SPAM UNDER CONTROL?
}

\author{
Carl J. Case, St. Bonaventure University, ccase@sbu.edu \\ Darwin L. King, St. Bonaventure University, dking@sbu.edu
}

\begin{abstract}
During the past few years, spam has invaded electronic mail boxes and become one of the major challenges for information systems (IS) professionals. Spam decreases user productivity, erodes electronic mail reliability, and requires the maintenance of spam-filtering software that drains the IS budget. Although spam is the largest type of electronic mail received, spam levels have begun to decrease. An important question, however, is whether the trend in industry is consistent among our undergraduate population. As a result, this paper empirically investigates spam incidence from a longitudinal perspective. Over 2,200 surveys from students enrolled in various School of Business courses were collected during a nine consecutive semester (four and one-half year) period. Electronic messaging was examined by type, gender, and semester. Results suggest that spam appears to have peaked and is dramatically decreasing both in quantity and as a percentage of total electronic mail received. Moreover, undergraduate spam incidence appears to be less prevalent than levels indicated in general population electronic mail. Gender, however, does not appear to be an important factor with regard to spam incidence. Another finding is that class-related electronic mail is now more common than personal electronic mail.
\end{abstract}

Keywords: Electronic Mail, Spam, Undergraduates, Empirical Survey, Gender

\section{INTRODUCTION}

Spam has been and continues to be a challenge for businesses. The Osterman Research Messaging Security Market Trends 2005-2008 survey, for example, found that for more than $60 \%$ of respondents, spam is the second most serious messaging issue for companies [9]. Small companies spend 9.1 hours per week per 1000 users to combat unsolicited messages while large companies spend 4.1 hours per week. One consequence is a $\$ 5.24$ to $\$ 9.78$ per user per month cost to protect e-messaging systems. A second result is lost productivity estimated to be $\$ 874$ per employee in 2003 and $\$ 1,934$ in 2004 [10]. The Radicati group further estimates that an organization with over 10,000 employees that does not use spam filtering could lose $\$ 2,933$ per year per user [7].

Spam can be defined as "unsolicited commercial email-- email that is sent by a company that has no existing business relationship with you to get you to buy something" [11]. Spam is so ubiquitous that it was even named the top "product" of 2003 by Basex, a research and consulting firm [16].

The history of spam, although relatively brief, has been spectacular. Brightmail, a spam-filtering company, estimated that in 2001, only $8 \%$ of electronic mail was spam [14]. In 2002, spam accounted for $40 \%$ of electronic mail. At that time, it also became the most commonly received type of message, surpassing even job-related messages [4]. MessageLabs Ltd., an electronic mail protection company, found that volume peaked at $94.5 \%$ in July of 1994 and decreased to $77 \%$ in January of 2005 [8]. MX Logic, another message-filtering company, found that by September of 2005, spam accounted for $67 \%$ of electronic mail [15].

Spam filtering and blocking programs have likely had a strong positive effect in combating the problem. Software packages such as Brightmail, SpamWeed, and SpamArrest are three of the most common programs available [13]. An InformationWeek research survey, for example, found that spamfiltering eliminated 54\% of spam in 2003 and $68 \%$ of spam in 2004 [8]. With anti-spam applications, the time spent on electronic mail drops from an average of 10 minutes to five minutes per day per user [5]. However, spam controls can erode the reliability of electronic mail systems [12]. Legitimate messages may end up in junk folders that recipients seldom check.

Two high-profile lawsuit settlements may have also had an effect on the level of spam. In June of 2005, Creaghan Harry agreed to settle charges brought against him by the Federal Trade Commission for $\$ 485,000$ [6]. In August of 2005, Scott Richter agreed to pay Microsoft $\$ 7$ million to settle a lawsuit and pledged to stop sending unsolicited electronic mail [3]. Richter's company, however, only represents .2\% of all spam. 
Students and universities are also not immune to the incidence of spam. Prior research has found that the majority of mail received by undergraduates is spam [2]. Because students spend a considerable amount of time in activities that could result in spyware being installed on his/her computer, spam may be more likely [1]. One study demonstrated that spyware incidence is prevalent, with an average of 141 spyware files found per student.

As a result, this paper explores undergraduate spam incidence from a longitudinal perspective to better describe the current state of undergraduate electronic behavior. Student messaging is examined to determine if student behavior is consistent with industry trends and if gender plays a role with regard to spam volume.

\section{RESEARCH DESIGN}

This study employs a longitudinal survey research design. The research was conducted at a private, northeastern U.S. University. A Student Electronic Mail survey instrument was developed and administered during a nine consecutive semester (four and one-half year) period to undergraduate students enrolled in a School of Business course. The semester range included the Fall 2001 to Fall 2005 semesters. The sample included a variety of courses such as BIS-310 "Business Information Systems", BIS 335 "System Analysis and Design”, ACCT-201 "Introduction to Financial Accounting", ACCT-202 "Introduction to Managerial Accounting", and MSC413 "Business Policy." A convenience sample of class sections was selected in order to maximize student participation. The class sections were conducted by a variety of faculty.

A survey instrument was utilized to collect student demographic data and examine student perceptions regarding his/her electronic mail behavior. The survey requested that each student estimate the average number of messages sent and received per week. The survey was administered during the final weeks of each semester and all surveys were anonymous. Moreover, students were informed that results would have no effect on their semester grade.

\section{RESULTS}

A sample of 2,226 usable surveys was obtained. Table 1 indicates that 1,362 (61\%) of the respondents were male and $864(39 \%)$ were female.
Table 1. Response Rate By Gender

\begin{tabular}{|l|c|}
\hline \multicolumn{1}{|c|}{ Gender } & Percentage \\
\hline Male & $61 \%$ \\
\hline Female & $39 \%$ \\
\hline Total & $100 \%$ \\
\hline
\end{tabular}

The response rate by academic class is relatively equally distributed among Freshmen, Sophomore, Junior, and Senior classes. Table 2 illustrates that $28 \%$ of respondents are freshmen, $25 \%$ are sophomores, $25 \%$ are juniors, and $22 \%$ are seniors.

Table 2. Response Rate By Academic Class

\begin{tabular}{|l|c|}
\hline \multicolumn{1}{|c|}{ Class } & Percentage \\
\hline Freshmen & $28 \%$ \\
\hline Sophomore & $25 \%$ \\
\hline Junior & $25 \%$ \\
\hline Senior & $22 \%$ \\
\hline
\end{tabular}

Table 3 depicts the quantity of electronic mail received per semester by category. During the study period, the average number of class-related electronic mail messages received increased by $59 \%$ from 7.1 to 11.3 messages per week. Non-class related electronic mail (personal mail to friends and family) decreased by $56 \%$ from 14.7 to 6.5 messages per week. Spam increased from 24.1 to 90.6 messages per week during the first four semesters and ultimately decreased to 13.6 during the last semester. Other electronic mail accounted for approximately 10 messages per week during the majority of the study semesters. The overall predominate category of electronic mail received during every semester was spam.

Table 4 illustrates spam received (as a percentage of total electronic mail) by gender. Results indicate that during five of the nine semesters, males received a higher percentage of spam. However, with the exception of two semesters, male and female percentages were nearly equal (within five percentage points). Overall, male spam incidence decreased from $53 \%$ to $30 \%$ of electronic mail. Female spam incidence decreased from $51 \%$ to $37 \%$ of electronic mail. Even prior to the university's implementation of a campus-wide spam filter during the Summer of 2004 , there was a dramatic decrease in spam levels. 
Table 3. Electronic Mail Received By Category

\begin{tabular}{|l|c|c|c|c|c|c|c|c|c|}
\hline Category & $\begin{array}{c}\text { Fall } \\
\mathbf{2 0 0 1}\end{array}$ & $\begin{array}{c}\text { Spring } \\
\mathbf{2 0 0 2}\end{array}$ & $\begin{array}{c}\text { Fall } \\
\mathbf{2 0 0 2}\end{array}$ & $\begin{array}{c}\text { Spring } \\
\mathbf{2 0 0 3}\end{array}$ & $\begin{array}{c}\text { Fall } \\
\mathbf{2 0 0 3}\end{array}$ & $\begin{array}{c}\text { Spring } \\
\mathbf{2 0 0 4}\end{array}$ & $\begin{array}{c}\text { Fall } \\
\mathbf{2 0 0 4}\end{array}$ & $\begin{array}{c}\text { Spring } \\
\mathbf{2 0 0 5}\end{array}$ & $\begin{array}{c}\text { Fall } \\
\mathbf{2 0 0 5}\end{array}$ \\
\hline Class-Related & 7.1 & 5.5 & 7.7 & 7.0 & 8.1 & 9.4 & 9.7 & 8.7 & 11.3 \\
\hline $\begin{array}{l}\text { Non Class-Related } \\
\text { (Friends, Family) }\end{array}$ & 14.7 & 9.9 & 7.9 & 9.3 & 6.6 & 7.1 & 5.0 & 4.8 & 6.5 \\
\hline Spam & 24.1 & 36.2 & 39.1 & 90.6 & 82.7 & 37.9 & 17.7 & 13.6 & 13.6 \\
\hline $\begin{array}{l}\text { Other (Notice Boards, } \\
\text { Clubs, etc.) }\end{array}$ & 15.0 & 10.7 & 14.4 & 16.6 & 10.8 & 9.8 & 10.4 & 10.4 \\
\hline Total & 45.9 & 66.5 & 65.4 & 121.3 & 114.1 & 65.2 & 42.2 & 37.5 & 41.7 \\
\hline
\end{tabular}

Table 4. Spam Received (as a Percentage of Total Electronic Mail) by Gender

\begin{tabular}{|l|c|c|c|c|c|c|c|c|c|}
\hline Gender & $\begin{array}{c}\text { Fall } \\
\mathbf{2 0 0 1}\end{array}$ & $\begin{array}{c}\text { Spring } \\
\mathbf{2 0 0 2}\end{array}$ & $\begin{array}{c}\text { Fall } \\
\mathbf{2 0 0 2}\end{array}$ & $\begin{array}{c}\text { Spring } \\
\mathbf{2 0 0 3}\end{array}$ & $\begin{array}{c}\text { Fall } \\
\mathbf{2 0 0 3}\end{array}$ & $\begin{array}{c}\text { Spring } \\
\mathbf{2 0 0 4}\end{array}$ & $\begin{array}{c}\text { Fall } \\
\mathbf{2 0 0 4}\end{array}$ & $\begin{array}{c}\text { Spring } \\
\mathbf{2 0 0 5}\end{array}$ & $\begin{array}{c}\text { Fall } \\
\mathbf{2 0 0 5}\end{array}$ \\
\hline Male & $53 \%$ & $57 \%$ & $60 \%$ & $74 \%$ & $73 \%$ & $61 \%$ & $39 \%$ & $35 \%$ & $30 \%$ \\
\hline Female & $51 \%$ & $52 \%$ & $59 \%$ & $76 \%$ & $71 \%$ & $38 \%$ & $47 \%$ & $38 \%$ & $37 \%$ \\
\hline
\end{tabular}

Spam quantity was next examined by gender (Table 5). Male spam quantity was initially 23.6 messages per week, peaked at 90.7 , and decreased to 12.5 messages per week. Female spam quantity was initially 25.1 messages per week, peaked at 106.6, and decreased to 15.6 messages per week. Analysis by gender demonstrates a nearly equal (within 6 messages) quantity for seven of the nine semesters, although female spam incidence was generally slightly higher than male quantity.

Table 5. Quantity of Spam Received by Gender

\begin{tabular}{|l|c|c|c|c|c|c|c|c|c|}
\hline Gender & Fall & $\begin{array}{c}\text { Spring } \\
\mathbf{2 0 0 1}\end{array}$ & $\begin{array}{c}\text { Fall } \\
\mathbf{2 0 0 2}\end{array}$ & $\begin{array}{c}\text { Spring } \\
\mathbf{2 0 0 3}\end{array}$ & $\begin{array}{c}\text { Fall } \\
\mathbf{2 0 0 3}\end{array}$ & $\begin{array}{c}\text { Spring } \\
\mathbf{2 0 0 4}\end{array}$ & $\begin{array}{c}\text { Fall } \\
\mathbf{2 0 0 4}\end{array}$ & $\begin{array}{c}\text { Spring } \\
\mathbf{2 0 0 5}\end{array}$ & $\begin{array}{c}\text { Fall } \\
\mathbf{2 0 0 5}\end{array}$ \\
\hline Male & 23.6 & 37.1 & 37.5 & 78.9 & 90.7 & 35.8 & 15.7 & 13.2 & 12.5 \\
\hline Female & 25.1 & 34.9 & 41.3 & 106.6 & 69.7 & 40.6 & 22.0 & 14.1 & 15.6 \\
\hline
\end{tabular}

\section{CONCLUSIONS AND FUTURE RESEARCH}

Results demonstrate that spam is the predominate category of electronic mail received. Spam accounted for $32-74 \%$ of electronic mail received per semester during the study period. In terms of volume, spam increased from 24.1 to 90.6 messages per week during the first four semesters and eventually decreased to 13.6 during the last semester. Classrelated, non-class-related, and other electronic mail were more linear in volume over time. The average number of class-related electronic mail messages received, for example, increased by $59 \%$ from 7.1 to 11.3 messages per week. Non-class related electronic mail (personal mail to friends and family) decreased by $56 \%$ from 14.7 to 6.5 messages per week. Other electronic mail accounted for approximately 10 messages per week during the majority of the study semesters.

Analysis by gender demonstrates that spam received (as a percentage of total electronic mail) is nearly equal for males and females. Although males received a higher percentage of spam during five of the nine semesters, during seven of the semesters, male and female percentages were nearly equal (within five percentage points). Overall, male spam incidence decreased from $53 \%$ to $30 \%$ of electronic mail. Female spam incidence decreased from $51 \%$ to $37 \%$ of electronic mail. In terms of volume, male 
spam quantity was 23.6 messages per week during the initial semester, peaked at 90.7, and decreased to 12.5 messages per week during the last study semester. Female spam quantity was 25.1 messages per week during the initial semester, peaked at 106.6, and decreased to 15.6 messages per week during the last study semester. Analysis by gender demonstrates a nearly equal (within 6 messages) quantity during $78 \%$ of the semesters examined although female spam incidence was generally slightly higher than male quantity.

There are several important implications as a result of these findings. One implication is that the previous spam explosion (evidenced in 2003) may be getting under control. Spam is decreasing both in volume and as a percentage of electronic mail received. Although spam peaked at 90.6 messages per week during the fourth semester, spam has decreased from 24.1 to 13.6 messages per week from the initial semester to the final semester of the nine semester study period. Spam filtering tools, implementation of spyware removal procedures, and more responsible computing behavior are likely strong factors contributing to the decrease in spam. Moreover, the recent successful litigation against spam-generating individuals may lead to lower spam levels in the future.

A second implication is that undergraduate spam incidence may be less than levels found in the general population. Spam-filtering companies indicate that in $2005,67-77 \%$ of electronic mail was spam. This study found that during the Fall 2005 semester, only $32 \%$ of undergraduate electronic mail was classified as spam. It is unknown, however, what percent of spam had already been filtered and removed prior to arriving in the student's inbox. However, prior to the introduction of the university-wide spam filter in the Summer of 2004, one spam-filtering company reported that $94.5 \%$ of electronic mail was spam. During the same time frame, this study found that only $56 \%$ of undergraduate electronic mail was spam.

A third implication is that undergraduates and faculty are using electronic mail for more productive purposes. Class-related electronic mail has increased by $59 \%$ and non-class-related electronic mail has decreased by $56 \%$. Moreover, students now report receiving nearly twice as many class-related messages than non-class-related messages. During the first study semester, students reported the opposite ratio. It is uncertain, however, why the productivity has dramatically increased with regard to electronic mail. One possible cause could be newer substitution communication technologies such as cell phones and instant messaging. Students may be using these quick and ubiquitous technologies as tools to communicate with friends and family.

Finally, findings suggest that gender does not appear to play a significant role in spam incidence. During $78 \%$ of the study semesters, male and female spam percentages of total electronic mail were nearly equal (within five percentage points). In addition, during $78 \%$ of the semesters examined, male and female spam volumes were nearly equal (within 6 messages). It is possible that spammers do not target individuals based upon gender or that undergraduate computing behavior is consistent among gender.

One limitation of this study is a function of sample size. A larger sample size, more equal distribution of respondents by gender, and use of additional universities would increase the robustness of results. Another limitation relates to the self-reported nature of the survey. Students are using recall to estimate activity thus recency effects may occur. In addition, the Hawthorne Effect may be evident. This effect is minimized due to respondent anonymity.

Future research should be directed toward examining which factors are most effective in decreasing spam incidence. Findings from such research would be useful in determining whether faculty and businesses need to implement or reevaluate instruction regarding responsible computing behavior. In addition, further research will need to be conducted to determine why undergraduate incidence varies from that found in the general population.

\section{REFERENCES}

1. Case, C. J. (2004). Spyware: An exploration of incidence and student perception. Issues in Information Systems, V(1), 63-69.

2. Case, C. J. and D. L. King (2005). Is undergraduate spam reaching an epidemic level? Business Research Yearbook, Global Business Perspectives, XII, 107-111.

3. Chabrow, E. (2005). In the fight against spam, a few knockouts. informationweek.com, 1052, 34.

4. Chen, A. (2002). How to slap spam. eweek, 19(33), 33-36.

5. Claburn, T. (2004). Anti-spam technologies prove their value. informationweek.com, 986, 55.

6. Claburn, T. (2005). 'Can-Spam' gets its man. informationweek.com, 1044, 14.

7. Claburn, T. (2005). The cost of spam. informationweek.com, 989, 18.

8. Claburn, T. (2005). Turning the tide. informationweek.com, 1022, 20-21. 
9. D'Antoni, H. (2005). Behind the numbers e-mail remains a point of vulnerability. informationweek.com, 1055, 74.

10. Evans, B. (2004). Time to stop playing cybersecurity chicken. informationweek.com, 993, 72.

11. Glass, B. (2002). Spam stoppers. PC Magazine, 21(9), 94.

12. Jesdanun, A. (2005). Spam controls risking email reliability. The Times Herald, February 28, A-10.
13. Khasawneh, R. and S. Ahmed (2004). Review and analysis of spam blocking applications. Issues in Information Systems, V(1), 152-158.

14. McCracken, H. (2003). Spam and punishment. www.pcworld.com, 21(8), 23.

15. Soat, J. (2005). Copyright, spam, and pamela anderson. informationweek.com, 1057, 16.

16. Techweb News. (2004). Product of the year: spam? informationweek.com, 970, 14. 